\title{
Effects of Additives in an Electrodeposition Bath on the Surface Morphologic Evolution of Electrodeposited Copper
}

\author{
Tsung-Wei Zeng ${ }^{1, *}$ and Shi-Chern Yen ${ }^{2}$ \\ ${ }^{1}$ Department of Chemical Engineering, Feng Chia University, Taichung, 407, Taiwan \\ ${ }^{2}$ Department of Chemical Engineering, National Taiwan University, Taipei, 106, Taiwan \\ *E-mail: twzeng@fcu.edu.tw
}

doi: $10.20964 / 2021.02 .40$

Received: 6 October 2020 / Accepted: 30 November 2020 / Published: 31 December 2020

\begin{abstract}
Additives in an electrodeposition bath have been frequently used to modulate the morphology of electrodeposited copper. The effects of gelatin, thiourea and chloride ions under various concentrations on electrodeposited copper were studied. The leveling and grain refining effects were identified for the use of gelatin. Thiourea acted as a grain-refining and brightening agent. Properly selected concentrations of gelatin or thiourea added in the electrodeposition bath made the adsorbed additives partly converge and optimized the leveling effects. The chloride ions increased the film roughness. In addition, the behaviors of the additives were studied based on polarization curves. Polarization contributed to the adsorption of gelatin and thiourea, which reduced the number of active sites and inhibited mass transport. The polarization curves indicate that the effects of chloride ions in combination with gelatin in the copper deposition were notably different from those of chloride ions alone. With the combination of gelatin, thiourea and chloride ions in proper concentrations, a copper deposited film with low roughness and high flatness can be obtained.
\end{abstract}

Keywords: electrodeposition; copper; gelatin; thiourea; chloride ions

\section{FULL TEXT}

(C) 2021 The Authors. Published by ESG (www.electrochemsci.org). This article is an open access article distributed under the terms and conditions of the Creative Commons Attribution license (http://creativecommons.org/licenses/by/4.0/). 